\title{
Fatal Septicaemia Following Suprapubic Cystostomy in a Paraplegic Patient: Never Do a Cystostomy without Prior Urine Culture and Appropriate Antibiogram!
}

\author{
Subramanian Vaidyanathan, ${ }^{1}$ Bakul M. Soni, ${ }^{1}$ Tun Oo, ${ }^{1}$ Peter L. Hughes, ${ }^{2}$ \\ and Gurpreet Singh ${ }^{3}$ \\ ${ }^{1}$ Regional Spinal Injuries Centre, District General Hospital, Southport, Merseyside PR8 6PN, UK \\ ${ }^{2}$ Department of Radiology, District General Hospital, Southport, Merseyside PR8 6PN, UK \\ ${ }^{3}$ Department of Urology, District General Hospital, Southport, Merseyside PR8 6PN, UK \\ Correspondence should be addressed to Subramanian Vaidyanathan, s.vaidyanathan@southportandormskirk.nhs.uk
}

Received 5 March 2010; Revised 23 April 2010; Accepted 11 May 2010

Academic Editor: Armin Curt

Copyright (C) 2010 Subramanian Vaidyanathan et al. This is an open access article distributed under the Creative Commons Attribution License, which permits unrestricted use, distribution, and reproduction in any medium, provided the original work is properly cited.

\begin{abstract}
Neuropathic urinary bladder is often colonised by multidrug-resistant bacteria. We report a 64-year-old male spinal cord injury patient with paraplegia, who received gentamicin on empirical basis before undergoing suprapubic cystostomy, as antibiotic sensitivity report of urine was not available. This patient developed fulminate septicaemia. Although appropriate antibiotic therapy (meropenem) was started when this patient manifested features of sepsis, acute renal failure occurred and he expired. Inappropriate initial antimicrobial therapy was the major contributory factor for this patient's mortality. Learning points from this case are (1) never do a cystostomy without prior urine culture and appropriate antibiogram; (2) in a chronic spinal cord injury patient, full blood count, liver function tests, albumin level, and albumin to globulin ratio should be performed before any surgical procedure.
\end{abstract}

\section{Introduction}

We report a spinal cord injury patient in whom suprapubic cystostomy was performed without prior urine culture and appropriate antibiogram. This patient received gentamicin on empirical basis but developed fulminate septicaemia and expired within forty-eight hours. Decreased natural and adaptive immune responses have been reported in patients with spinal cord injury [1-3]. However, it remains unclear if a reduced immune response, which is pronounced in the acute phase after spinal cord injury, plays a relevant role in this patient seven years after spinal cord injury.

\section{Case Presentation}

A British Caucasian male patient, born in 1946, fell down from a ladder in 2002 and sustained concussional brain injury, soft tissue injury to left shoulder, burst fracture of thoracic vertebrae 4, 5, and 6, paraplegia T-5 (American
Spinal Injury Association grade B), multiple rib fractures and mediastinal haematoma. Following rehabilitation, this patient had been managing his bladder by long-term indwelling catheter drainage.

In June 2009, he developed temperature of 38.8 degrees Celsius. White cell count was high $\left(18.1 \times 10^{9} / \mathrm{L}\right)$. Neutrophils were increased $\left(15.85 \times 10^{9} / \mathrm{L}\right)$. C-reactive protein was elevated $(121.1 \mathrm{mg} / \mathrm{L})$. Total protein: $65 \mathrm{~g} / \mathrm{L}$. Albumin: $39 \mathrm{~g} / \mathrm{L}$. Globulin: $26 \mathrm{~g} / \mathrm{L}$. Urine microbiology showed growth of Klebsiella pneumoniae, which produced an extended spectrum beta-lactamase and multiresistant. This patient was prescribed gentamicin $320 \mathrm{mg}$ once daily. In October 2009, this patient again developed urine infection. Creactive protein was high at $165.8 \mathrm{mg} / \mathrm{L}$. Total protein: $69 \mathrm{~g} / \mathrm{L}$. Albumin: $38 \mathrm{~g} / \mathrm{L}$. Globulin: $31 \mathrm{~g} / \mathrm{L}$. Haemoglobin was $12.7 \mathrm{~g} / \mathrm{dL}$. Urine showed growth of Escherichia coli; antibiotic sensitivity report was not available. This patient was prescribed meropenem, one gram intravenously every eight hours. While the patient received meropenem, another 
sample of urine was sent for microbiology; this sample of urine showed no growth. Intravenous urography was performed in November 2009 to exclude stones in the upper urinary tract as a reason for the recurrent urinary tract infection. No renal or ureteric calculi were found.

In January 2010, this patient decided to undergo suprapubic cystostomy so that he could discard permanent catheter in the penis. At the time of undergoing suprapubic cystostomy, this patient was feeling well; he did not have symptomatic urine infection. He did not suffer from any comorbid condition such as diabetes mellitus, pressure sore, ischaemic heart disease, hypertension, or mental health problem. This patient had Medtronic programmable pump implanted for intrathecal administration of baclofen for control of spasticity. His medications were senna syrup, sugar-free, $30 \mathrm{mg}$ on alternate evenings; Micralax Microenema $5 \mathrm{~mL}$ on alternate mornings; oxybutynin modified release $10 \mathrm{mg}$, once daily. Neither blood tests nor urodynamics were performed prior to suprapubic cystostomy. He was given gentamicin $240 \mathrm{mg}$ intravenously, as antibiotic sensitivity report of urine sample was not available to physicians treating this patient. Suprapubic cystostomy was performed in the outpatient department using Add a Cath. The urinary bladder was located by ultrasound scan. The procedure was carried out uneventfully. Following suprapubic cystostomy, there was mild haematuria. Two hours later, this patient was feeling unwell; he had tachycardia, spasms, and cold fingers. Temperature was 38 degrees Celsius; oxygen saturation was $97 \%$; urine was stained with blood; there was some oozing of blood from suprapubic cystostomy site. Suprapubic catheter was patent. Diagnosis was septicaemia. He had received one dose of gentamicin $240 \mathrm{mg}$ intravenously. Subsequently, a review of laboratory reports revealed that in October 2009, urine showed growth of coliforms, sensitive to meropenem. Therefore, this patient was prescribed meropenem 1 gram intravenously every eight hours. He was given fluids intravenously. A Foley catheter was inserted per urethra. Blood culture was taken. This blood culture yielded growth of Escherichia coli; however, antibiotic sensitivity was not available. Full blood count revealed low white cell count of $2.7 \times 10^{9} / \mathrm{L}$, which indicated severe sepsis. Blood test showed Total Protein: $72 \mathrm{~g} / \mathrm{L}$; Albumin: $40 \mathrm{~g} / \mathrm{L}$; Globulin: $32 \mathrm{~g} / \mathrm{L}$.

Sixteen hours after undergoing suprapubic cystostomy, this patient was afebrile. He was breathing spontaneously with $40 \%$ oxygen by nasal mask. Heart rate was 93 per minute; Blood pressure was $80 / 33 \mathrm{~mm} \mathrm{Hg}$; respiratory rate was 16 per minute. There was peripheral cyanosis; capillary circulation return time was greater than two seconds. Examination of chest revealed bilateral equal air entry and vesicular breath sounds. Abdomen was soft and bowel sounds were present. Clinical impression was septicaemia and hypovolaemia. Rate of administration of intravenous fluids was increased to $160 \mathrm{~mL}$ per hour. Arterial blood gas showed pH: 7.393; pCO2: $5.87 \mathrm{kPa}$; pO2: $8.25 \mathrm{kPa}$; actual bicarbonate: $26.2 \mathrm{mmol} / \mathrm{L}$; standard bicarbonate: $25.2 \mathrm{mmol} / \mathrm{L}$; base excess: $1.0 \mathrm{mmol} / \mathrm{L}$. Full blood count showed leucocytosis $\left(15.6 \times 10^{9} / \mathrm{L}\right)$; neutrophils count was high $\left(15.3 \times 10^{9} / \mathrm{L}\right)$. APTT ratio was high at 1.40 (reference range: $0.84-1.16$ ). C-reactive protein was high at $123.1 \mathrm{mg} / \mathrm{L}$. Blood urea: $9.1 \mathrm{mmol} / \mathrm{L}$; creatinine: $148 \mathrm{micromol} / \mathrm{L}$; sodium: $133 \mathrm{mmol} / \mathrm{L}$; potassium: $4.3 \mathrm{mmol} / \mathrm{L}$.

Thirty-four hours after performing suprapubic cystostomy, this patient was found to be confused. Heart rate was 113 per minute; blood pressure was $119 / 63 \mathrm{~mm} \mathrm{Hg}$. Physical examination revealed clear chest; abdomen was silent; penis was oedematous. Blood tests showed sodium: $133 \mathrm{mmol} / \mathrm{L}$; potassium: $4.3 \mathrm{mmol} / \mathrm{L}$; urea: $9.1 \mathrm{mmol} / \mathrm{L}$; creatinine $148 \mathrm{micromol} / \mathrm{L}$. This patient was given intravenous infusion of succinylated gelatine (Gelofusine) $500 \mathrm{~mL}$. Even after this fluid challenge, urine output was only $15 \mathrm{~mL}$. Both urinary catheters were patent. On clinical examination, abdomen was soft and nontender. Urinary bladder was not palpable; suprapubic wound was healthy; penis was very oedematous.

Thirty-six hours after undergoing suprapubic cystostomy, this patient was in renal failure; urine output was $5 \mathrm{~mL}$ in two hours. Full blood count showed very high white cell count $\left(23.6 \times 10^{9} / \mathrm{L}\right)$. Haemoglobin was slightly low at $10.5 \mathrm{~g} / \mathrm{dL}$. Platelet count was also low at $12 \times 10^{9} / \mathrm{L} 1$. Neutrophils were greatly increased $\left(22.4 \times 10^{9} / \mathrm{L}\right)$. Blood urea had risen to $16.4 \mathrm{mmol} / \mathrm{L}$. Creatinine concentration also had increased to $253 \mathrm{micromol} / \mathrm{L}$. Sodium was low at $127 \mathrm{mmol} / \mathrm{L}$. Potassium level had increased from $4.3 \mathrm{mmol} / \mathrm{L}$ to $5.4 \mathrm{mmol} / \mathrm{L}$. This patient developed cardiac arrest 38 hours after suprapubic cystostomy. After 28 minutes of unsuccessful resuscitation, he was declared dead. Patient's wife did not give permission for autopsy.

\section{Discussion}

Iatrogenic bowel injury is a recognized complication of percutaneous suprapubic cystostomy [4]. For safe placement of a suprapubic catheter, the patients must have an adequately distended bladder and be placed in Trendelenburg position that allows safe extraperitoneal puncture of the bladder. In this patient, suprapubic cystostomy was performed under ultrasound guidance after filling the bladder with $0.9 \%$ sodium chloride through urethral catheter. When this patient developed septicaemia, there were no clinical features of peritonitis such as abdominal distension, guarding, rigidity, or rebound tenderness. In spinal cord injury patients, normal clinical signs for peritonitis can be absent due to sensory deficits. Therefore, computed tomography of abdomen should be performed in spinal cord injury patients to rule out intraabdominal pathology such as bowel perforation or extravasation of urine. We should have carried out autopsy to ascertain the precise cause of death especially in this patient, who died within 48 hours after undergoing a surgical procedure.

Spinal cord injury produces profound alterations in lower urinary tract function such as incontinence, elevated intravesical pressure, vesicoureteric reflux, renal stones, vesical calculi, and detrusor-sphincter dyssynergia, which increase the risk of urinary infection in these patients [5]. Further, colonisation of neuropathic urinary bladder by multidrug-resistant bacteria is not uncommon in spinal cord 
injury patients. In a study of 145 patients suffering from spinal cord injuries, admitted to the Institute for physical medicine and rehabilitation, Centre for paraplegia of the Clinical Centre of the University of Sarajevo [6], a total of 4539 urine samples were obtained for microbiology. Of these urine samples, $3963(87.3 \%)$ were positive and $576(12.7 \%)$ were sterile. $55.3 \%$ of isolates were multidrug resistant, and the highest rates of resistance were found among Acinetobacter baumannii (87.8\%), Providencia rettgeri (86.7\%), Pseudomonas aeruginosa (85.4\%), Providencia stuarti (84.3\%), and Morganella morganii (81.0\%).

Waites et al. [7] studied urine samples from two hundred eighty-seven patients with spinal cord injury, who attended clinics. There were 706 gram-negative isolates from 444 urine specimens. Occurrence of bacteriuria with gram-negative organisms demonstrating resistance to antimicrobial agents in 2 or more classes was observed in $33 \%$ of bacterial isolates.

In spinal cord injury patients, antibiotic therapy is only indicated in symptomatic bacteriuria or in symptomatic exacerbations of chronic urine infection [8]. A study of 38 patients with spinal cord injury, who underwent 51 urologic procedures between January 2004 and June 2005, revealed that twenty-six patients needed antimicrobials other than gentamicin (piperacillin/tazobactam, cefotaxime, ceftazidime, imipenem/cilastatin, ciprofloxacin, co-amoxiclav, or amikacin) because uropathogens were resistant to gentamicin [9]. These pathogens consisted of Pseudomonas aeruginosa (7 isolates), Escherichia coli (6 isolates), Klebsiella species (10 isolates), Serratia marcescens (2 isolates), Enterobacter species (2 isolates), and Staphylococcus aureus (1 isolate).

Presence of multidrug-resistant bacteria in urine of spinal cord injury patients warrants administration of appropriate antibiotic(s) before performing any urological procedure and continued for $24-48$ hours. If a spinal cord injury patient receives antibiotics to which urinary bacteria are resistant, such a patient may develop bacteraemia and septicaemia following an invasive urological procedure, as indeed happened to our patient.

Kumar et al. [10] showed that the inappropriateness of initial antimicrobial therapy remained most highly associated with risk of death in patients with septicaemia, as exemplified by this case. Delays to appropriate antimicrobial therapy have been shown to contribute to significant increases in the incidence of acute kidney injury [11]. Our patient, who was given gentamicin on empirical basis developed septicaemia and renal failure after uneventful suprapubic cystostomy. He developed cardiac arrest before we could organise haemofiltration.

We did not perform blood tests prior to suprapubic cystostomy. In hindsight, we realise our mistake. In a chronic spinal cord injury patient, full blood count, liver function tests, albumin level, and albumin to globulin ratio should be performed before any surgical procedure. If blood tests show any nutritional deficit, such deficit should be corrected before performing any surgical procedure. Correction of nutritional deficiency is even more important than dual antibiotic therapy in a chronically ill patient.

\section{Conclusion}

(1) A sample of urine should be sent for microbiology in all spinal cord injury patients prior to major urological procedures such as suprapubic cystostomy, removal of stones from urinary tract, insertion of urinary stents, nephrostomy, urethral sphincterotomy, bladder neck resection, and urethrotomy. Antibiotic sensitivity report of urine should be available to physicians, who treat spinal cord injury patients.

(2) Appropriate antibiotic(s) should be prescribed in adequate doses on the basis of recent urine microbiologic test results immediately before performing urological procedure and continued for $24-48$ hours. Never do a cystostomy without prior urine culture and appropriate antibiogram!

(3) If antibiotic sensitivity report of recent urine sample is not available, dual antimicrobial therapy consisting of an aminoglycoside (gentamicin or amikacin), and either carbapenem (imipenem with cilastatin or meropenem) or antipseudomonal penicillin (piperacillin with tazobactam) should be given to spinal cord injury patients undergoing urological procedures until microbiology report is available.

(4) If a spinal cord injury patient develops features of sepsis after undergoing suprapubic cystostomy, computed tomography of abdomen should be performed to look for silent bowel perforation or extravasation of urine, as normal clinical signs for peritonitis can be absent due to sensory deficits.

(5) Long-term urethral catheter drainage is not the ideal method of managing neuropathic bladder in spinal cord injury patients. All efforts should be made to discard indwelling urinary catheter and start intermittent catheterisation regime. Never leave a patient on Foley catheter for seven years!

\section{Acknowledgment}

The authors are grateful to Ms Jacquie McGarry, Senior Territory Manager, Hollister Continence Care Division, Rectory Court, 2 Broad Street, Wokingham, Berks RG40 $1 \mathrm{AB}$, UK for the valuable help towards payment of article processing fee for this paper.

\section{References}

[1] J. M. Cruse, J. C. Keith, M. L. Bryant Jr., and R. E. Lewis Jr., "Immune system-neuroendocrine dysregulation in spinal cord injury," Immunologic Research, vol. 15, no. 4, pp. 306-314, 1996.

[2] J. M. Cruse, R. E. Lewis, S. Dilioglou, D. L. Roe, W. F. Wallace, and R. S. Chen, "Review of immune function, healing of pressure ulcers, and nutritional status in patients with spinal cord injury," Journal of Spinal Cord Medicine, vol. 23, no. 2, pp. 129-135, 2000.

[3] K. M. Lucin, V. M. Sanders, T. B. Jones, W. B. Malarkey, and P. G. Popovich, "Impaired antibody synthesis after spinal cord 
injury is level dependent and is due to sympathetic nervous system dysregulation," Experimental Neurology, vol. 207, no. 1, pp. 75-84, 2007.

[4] C.-C. Wu, C.-T. Su, and A. C.-M. Lin, "Terminal ileum perforation from a misplaced percutaneous suprapubic cystostomy," European Journal of Emergency Medicine, vol. 14, no. 2, pp. 92-93, 2007.

[5] M. B. Siroky, "Pathogenesis of bacteriuria and infection in the spinal cord injured patient," American Journal of Medicine, vol. 113, supplement 1, pp. 67S-79S, 2002.

[6] A. Dedeić-Ljubović and M. Hukić, "Catheter-related urinary tract infection in patients suffering from spinal cord injuries," Bosnian Journal of Basic Medical Sciences, vol. 9, no. 1, pp. 2-9, 2009.

[7] K. B. Waites, Y.-Y. Chen, M. J. DeVivo, K. C. Canupp, and S. A. Moser, "Antimicrobial resistance in gram-negative bacteria isolated from the urinary tract in community-residing persons with spinal cord injury," Archives of Physical Medicine and Rehabilitation, vol. 81, no. 6, pp. 764-769, 2000.

[8] K. Everaert, N. Lumen, W. Kerckhaert, P. Willaert, and M. van Driel, "Urinary tract infections in spinal cord injury: prevention and treatment guidelines," Acta Clinica Belgica, vol. 64, no. 4, pp. 335-340, 2009.

[9] S. Vaidyanathan and B. M. Soni, "Antibiotic therapy for patients with spinal cord injury undergoing urologic procedures," Advances in Therapy, vol. 23, no. 1, pp. 92-97, 2006.

[10] A. Kumar, P. Ellis, Y. Arabi, et al., "Initiation of inappropriate antimicrobial therapy results in a fivefold reduction of survival in human septic shock," Chest, vol. 136, no. 5, pp. 1237-1248, 2009.

[11] S. M. Bagshaw, S. Lapinsky, S. Dial, et al., "Acute kidney injury in septic shock: clinical outcomes and impact of duration of hypotension prior to initiation of antimicrobial therapy," Intensive Care Medicine, vol. 35, no. 5, pp. 871-881, 2009. 


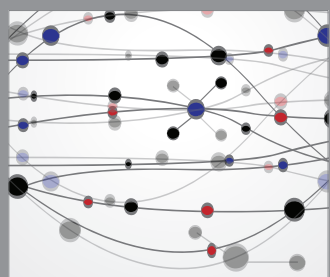

The Scientific World Journal
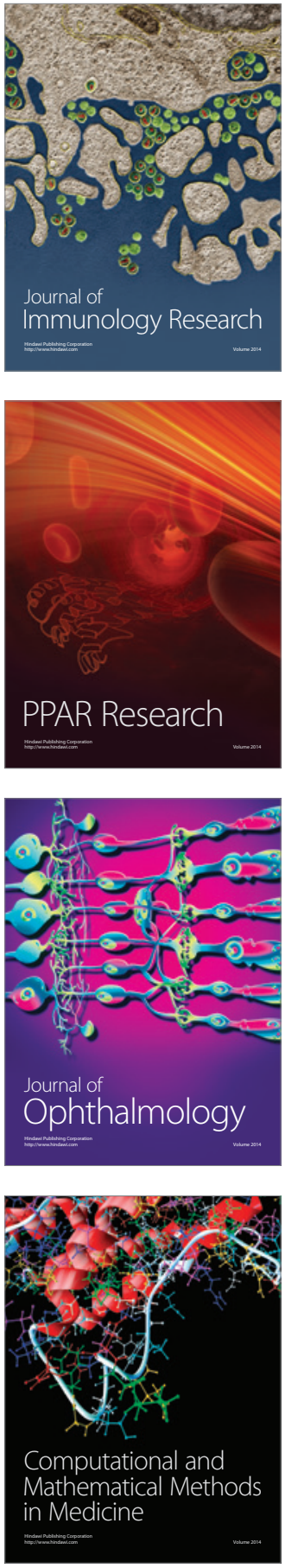

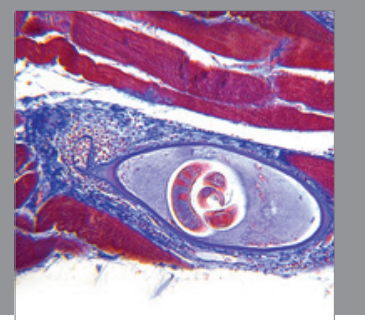

Gastroenterology

Research and Practice
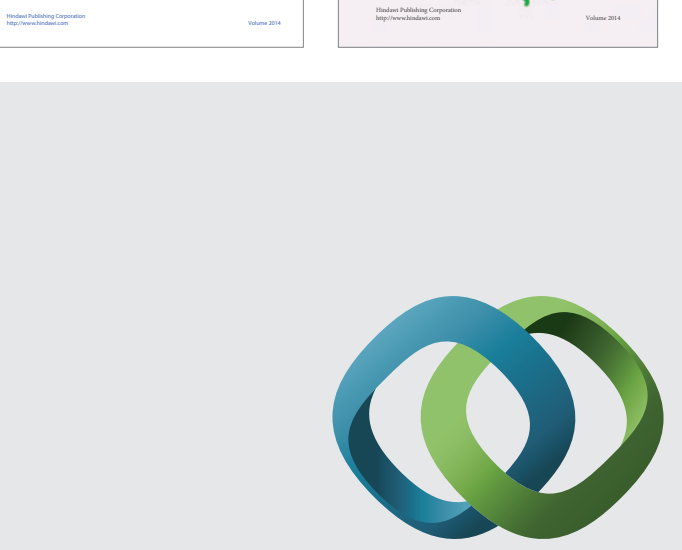

\section{Hindawi}

Submit your manuscripts at

http://www.hindawi.com
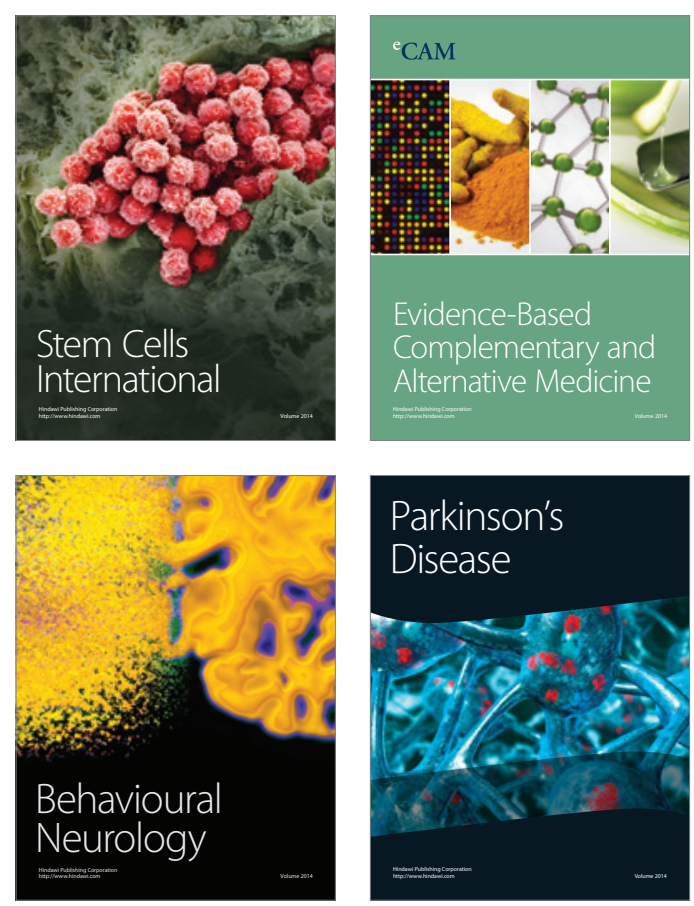

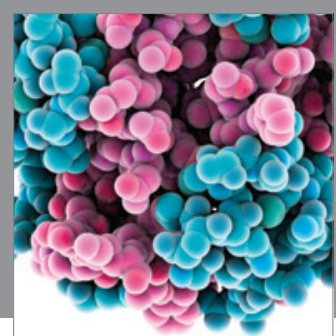

Journal of
Diabetes Research

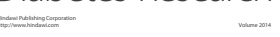

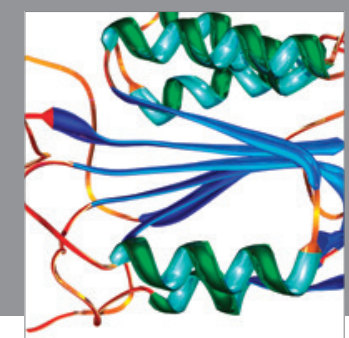

Disease Markers
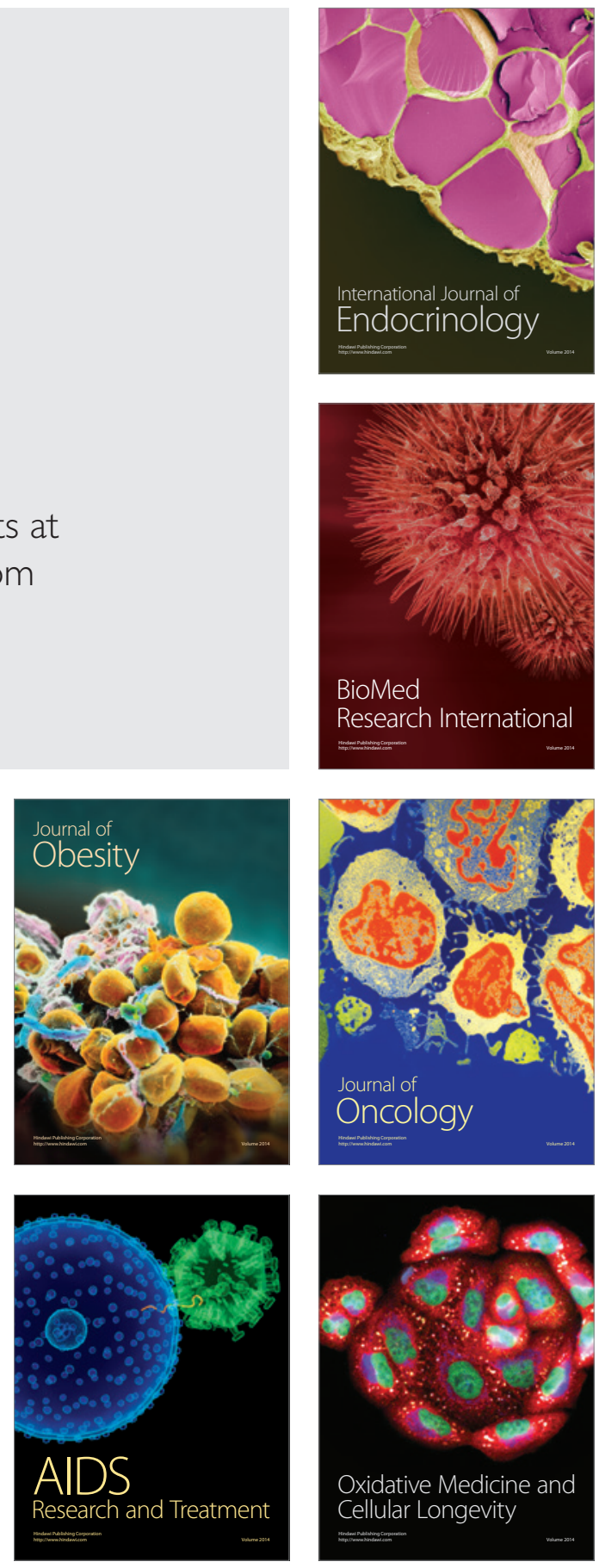